\begin{tabular}{cc|c}
\hline Tar. Bil. Der. & Journal of Agricultural Sciences \\
& $\begin{array}{c}\text { Dergi web sayfası: } \\
\text { www.agri.ankara.edu.tr/dergi }\end{array}$ & Journal homepage: \\
& www.agri.ankara.edu.tr/journal
\end{tabular}

\title{
Enginarın Basınçlı Havayla, Suyla ve Vakumla Ön Soğutulmasının Depolama Koşullarındaki Kalite Parametreleri Üzerindeki Etkisinin Belirlenmesi
}

\author{
İlknur ALİBAŞ ${ }^{\mathrm{a}}$, Rasim OKURSOY ${ }^{\mathrm{a}}$ \\ ${ }^{a}$ Uludag Universiesi, Ziraat Fakültesi, Biyosistem Mühendisliği Bölümü, 16059, Bursa, TÜRKIYE
}

\section{ESER BILGISII}

Araştırma Makalesi DOI: 10.1501/Tarimbil_0000001406

Sorumlu Yazar: İlknur ALİBAŞ, E-posta: ialibas@uludag.edu.tr, Tel: +90 (224) 2941608

Geliş Tarihi: 28 Ocak 2015, Düzeltmelerin Gelişi: 27 Haziran 2015, Kabul: 29 Haziran 2015

\begin{abstract}
ÖZET
Bu çalışmada, havayla, suyla ve vakumla ön soğutma yöntemleri kullanılarak $5 \pm 0.005 \mathrm{~kg}$ ağırlıkta tartılarak kasalara yerleştirilen enginarların tarla sıcaklığı olan $23.5 \pm 0.5{ }^{\circ} \mathrm{C}$ 'den depolama sıcaklığı olan $1{ }^{\circ} \mathrm{C}$ 'ye kadar soğutulması sağlanmıştır. Ön soğutma zamanı en kısa olan soğutma yöntemi 35 dakika ile vakumla ön soğutma yöntemidir. Bunu sırasıyla 58 dakika ile suyla ve 135 dakika ile havayla ön soğutma yöntemleri izlemiştir. Ön soğutma sistemleri enerji tüketimleri açısından incelendiğinde ise en az enerji tüketimi $0.38 \mathrm{kWh}$ değeri ile vakumla ön soğutma sisteminde saptanmıştır. Bunu sırasıyla $0.65 \mathrm{kWh}$ değeri ile suyla ve $0.84 \mathrm{kWh}$ değeri ile de havayla ön soğutma sistemleri izlemiştir. Sistemlerin tükettikleri güç açısından yapılan değerlendirmeye göre en az gücün $0.37 \mathrm{~kW}$ değeri ile basınçlı havayla ön soğutma sistemi olduğu, bunu sırasıyla $0.48 \mathrm{~kW}$ değeri ile suyla ve $0.65 \mathrm{~kW}$ değeri ile vakumla ön soğutmanın izlediği belirlenmiştir. Ön soğutma işlemleri sonunda suyla ön soğutulmuş ürünlerde \% 2.83 oranında bir ağırlık artışı gözlemlenmiştir. Buna karşın basınçlı havayla ve vakumla ön soğutulmuş enginarlarda ise soğutma işlemi sonrasında sırasıyla \% 1.03 ve \% 1.88 oranında ağırlık azalması meydana geldiği saptanmıştır. Basıç̧lı havayla, suyla ve vakumla ön soğutulmuş ve hiç ön soğutulmamış (kontrol) enginarlar kontrollü atmosfer odasında 30 gün, oda koşullarında ise 15 gün boyunca bekletilmiş ve meyve eti sertliği, ağırlık kaybı, bozulma oranı ve genel görünümleri açısından değerlendirilmiştir. Buna göre enginarlarda kalite parametreleri açısından en uygun ön soğutma yönteminin havayla ön soğutma olduğu; bunu sırasıyla vakumla, kontrol koşullarında ve suyla ön soğumanın izlediği saptanmıştır.
\end{abstract}

Anahtar Kelimeler: Basınçlı havayla ön soğutma; Enginar; Kalite parametreleri; Suyla ön soğutma; Vakumla ön soğutma

\section{Determination of Quality Parameters during Air Blast, Vacuum and Hydro Pre-cooling of Artichoke under the Storage Conditions}

\author{
ARTICLE INFO \\ Research Article \\ Corresponding Author: İlknur ALİBAŞ, E-mail: ialibas@uludag.edu.tr, Tel: +90 (224) 2941608 \\ Received: 28 January 2015, Received in Revised Form: 27 June 2015, Accepted: 29 June 2015
}




\begin{abstract}
The aim of the present study is to pre-cool artichokes which were placed in the cases after weighing $5 \pm 0.005 \mathrm{~kg}$, from $23.5 \pm 0.5{ }^{\circ} \mathrm{C}$ which is field temperature to the storage temperature of $1{ }^{\circ} \mathrm{C}$ through using three different precooling methods such as air blast, hydro and vacuum. The cooling method, which has the shortest pre-cooling time, is the vacuum pre-cooling method with 35 minutes. This was followed by hydro with 58 minutes and air pre-cooling method with 135 minutes. When pre-cooling systems were analyzed in terms of energy consumption, vacuum precooling system was determined to have the lowest energy consumption with the value of $0.38 \mathrm{kWh}$, which was followed by hydro pre-cooling with $0.65 \mathrm{kWh}$ and air pre-cooling system with $0.84 \mathrm{kWh}$. Based upon an evaluation carried out in terms of power consumption of the systems, air blast pre-cooling method has the minimum power with the value of $0.37 \mathrm{~kW}$, which was followed by hydro and vacuum pre-cooling methods with the respective values of $0.48 \mathrm{~kW}$ and $0.65 \mathrm{~kW}$. Following pre-cooling operations, it was observed that there is $2.83 \%$ weight gain in the products exposed to hydro pre-cooling. However, $1.03 \%$ and $1.88 \%$ weight loss was found to occur after pre-cooling operation in artichokes pre-cooled by means of air blast and vacuum. Artichokes pre-cooled through air blast, hydro and vacuum or those which are not pre-cooled were maintained for 30 days in modified atmosphere room while they were hold for 15 days in room conditions; moreover, they were analyzed related to weight loss, hardness, degradation rate and overall appearance. Accordingly, it was determined that the most suitable pre-cooling method is vacuum pre-cooling; this was followed by artichokes pre-cooled though vacuum and hydro or those not pre-cooled.
\end{abstract}

Keywords: Air precooling; Artichoke; Hydro precooling; Quality parameters; Vacuum precooling

(C) Ankara Üniversitesi Ziraat Fakültesi

\section{Giriş}

Anayurdu, Akdeniz ülkeleri olan enginar (Cynara cardunculus L.), toprağı zengin, iklimi yumuşak ve nemli olan pek çok ülkede yetiştirilmektedir (Romani et al 2006). Enginar içerdiği mineraller bakımından oldukça zengin bir sebzedir. Bol miktarda potasyum, kalsiyum ve mangan ile A, B1 ve C vitaminleri içermektedir. Enginar ayrıca, karaciğeri temizlemesi, kanı sulandırması, özellikle LDL-kolesterolü düşürücü etkiye sahip olması ve safranın kolay akışını sağlaması gibi özelliklere de sahiptir (Thompson Coon \& Ernst 2003; Zhu et al 2004; Zhu et al 2005; Günhan et al 2014).

Tarımsal ürünler hasat edilmelerinin peşi sıra bünyelerindeki mikroorganizma faaliyetlerinin ve etilen gazı oluşumunun hızlanması, su kaybının oluşmaya başlaması ve solunumun yavaşlaması gibi nedenlerden dolayı bozulmaya başlarlar (Alibaş 2012). Hasat işlemini takip eden süreçteki bu bozulmaların önüne geçilebilmesi için hasat sonrası meyve ve sebzelerin tarla sicaklığından depolama sıcaklığına kadar hızla düşürülmesi yani "ön soğutulması" gerekmektedir (Sankat \& Mujaffar
1999; Wang \& Sun 2001; Brosnan \& Sun 2003; Sun \& Wang 2004; Alibaş \& Okursoy 2009).

Ön soğutma işlemleri soğutulacak ürünün özelliklerine ve uygulanacak teknolojiye göre genel olarak üç farklı yöntemle yapılmaktadır. Bu yöntemler; havayla, suyla ve vakumla ön soğutma yöntemleridir (Alibaş \& Okursoy 2012). Havayla ön soğutma yöntemi bilinen en eski soğutma tekniğidir. Soğutucu akışkan olarak kullanılan havanın soğutulacak olan materyalin bulunduğu ortama gönderilmesi ile havayla ön soğutma işlemi gerçekleştirilmektedir. Hasat sıcaklığındaki ürün, soğuk havanın etkisi ile dış yüzeyden başlayarak iç yüzeye doğru konveksiyon yoluyla soğutulmaktadır (Alibas \& Koksal 2014). Suyla ön soğutma yönteminde soğutulmuş su, soğutucu akışkan olarak sisteme verilir ve ürünlerin soğuması tıpkı havayla ön soğutma yöntemindeki gibi konveksiyon yoluyla sağlanmaktadır (Alibaş \& İzli 2013). Bu yöntemin en büyük avantajı çeşitli ürün artıklarının, tarla tozu ve kirinin üründen yıkanıp temizlenmesine ve soğutma suyuna ilave edilen klor ve iyot çözeltileri gibi bazı kimyasal maddeler ile ürün yüzeyindeki zararlı bakterilerin yok edilmesine 
olanak sağlanmasıdır (Alibaş \& Okursoy 2009). Suyla soğutma yönteminde ürünün donmaması için bazı koruma önlemlerinin alınması gerekmektedir. Ayrıca suyla soğutma yöntemi ile soğutulacak ürünlerin ve kullanılan ambalaj malzemelerinin suya dayanıklı olması gerekmektedir (Alibaş \& İzli 2013).

Vakumla soğutma tekniği ise ürünün bünyesinde bulunan suyun buharlaştırılması ile ürün sıcaklığının hızlı bir şekilde azalması prensibine dayanmaktadır (Brosnan \& Sun 2003; Alibas \& Koksal 2014). Soğutma sistemindeki basıncın sürekli olarak azalması ile materyalin bünyesindeki buharlaşmanın sürekli kalması sağlanmaktadır. Vakumla soğutma işlemi sırasında, materyalin bünyesinde serbest halde bulunan su, kaynama noktasına yakın bir sıcaklık değerinde buharlaşmaktadır (Dostal \& Petera 2004). Ürün vakuma maruz bırakıldığında, ürünün bünyesinde bulunan suyun kaynama sıcaklığı düşmekte ve suyun bir kısmı yeni denge şartları oluşana dek kaynamaktadır (Wang \& Sun 2004). Vakumla soğutma işleminin başlaması ile materyalin iç kısmında bulunan su, düşük basıncın etkisi ile kaynayarak materyalin dış kısımlarına çıkmakta ve dış kısmından da buharlaşmaktadır. $\mathrm{Bu}$ buharlaşma sırasında ortamdan 1sı çekildiği için tarımsal ürünler soğumaktadır. Vakumla soğutma ile soğutma süresinde önemli ölçüde azalma sağlanmaktadır (McDonald \& Sun 2000; McDonald et al 2002; Houska et al 2003; Sun \& Wang 2004; Wang \& Sun 2004).

Ön soğutma işlemlerinden sonra soğutulmuş ürünler, soğutma sıcaklığı korunarak ya satışa gönderilmekte ya da soğuk havada depolanmaktadır (Alibaş \& Okursoy 2012). Ürünün satışa sunulmadan önce soğutulması, genellikle soğutma kapasitesi düşük olan taşıyıcı araçların soğutma yükünü azaltmaktadır. Depolanacak ürünlere daha önceden ön soğutma yapılması, soğuk depolama sırasında harcanan soğutma gücünden tasarruf sağlanmasina da olanak sağlamaktadır (Alibas \& Koksal 2015).

$\mathrm{Bu}$ çalışmanın amacı; i) yeni hasat edilmiş enginar bitkisinin havayla, suyla ve vakumla ön soğutulmasını sağlamak, ii) ön soğutma süresi, ağırlık fark1, sistemlerin enerji ve güç tüketimlerini tespit etmek ve iii) ön soğutulmuş ürünlerin hem kontrollü atmosfer odasında hem de oda koşullarındaki kalite parametrelerinin belirlenmesiyle enginar bitkisi için en uygun ön soğutma yöntemini saptamaktır.

\section{Materyal ve Yöntem}

\section{1. Örneklerin hazırlanması}

Soğutulacak olan enginar (Cynara cardunculus L. var. scolymus (L.) Fiori), Bursa ili Osmangazi İlçesi Nilüfer Köy'de üretim yapan bir üreticiden yeni hasat edilmiş olarak alınmıştır. Enginarlar hasat sıcaklığı korunarak hızlı bir şekilde laboratuvar ortamına taşınmış ve vakit kaybetmeden ön soğutma işlemlerine tabi tutulmuştur.

\section{2. Ön soğutma sistemleri}

\subsubsection{Havayla ön soğutma sistemi}

Genel görünümü Şekil 1(a)'da verilmiş olan basınçlı havayla ön soğutma sistemi; soğutma kabini, fan, kontrol panosu ve içinde buharlaştırıcı, yoğuşturucu, kompresör, genleşme valfi ve soğutucu akışkan bulunan soğutucu üniteden oluşmaktadır. Soğutma kabini $2 \mathrm{~mm}$ kalınlığındaki galvanizli sacdan boyutlar1 $850 \times 800 \times 1100 \mathrm{~mm}$, hacmi ise 0.748 $\mathrm{m}^{3}$ olacak şekilde tasarlanmıştır. Soğutma kabininin çevresine, $12 \mathrm{~mm}$ kalınlığında $0.147 \mathrm{~kJ} \mathrm{~m}^{-2} \mathrm{~h}^{\circ} \mathrm{C}$ 1sı geçiş katsayısına sahip cam yünü sarılmış olup soğutma kabininin arka duvarına buharlaştırıcı ve buharlaştırıcının hemen üzerine ise devir sayısı 1400 dakika $^{-1}$ olan $160 \mathrm{~mm}$ çark çapına sahip 5 kanatlı aksiyal bir fan yerleştirilmiştir. Sistem sıcaklığı dijital bir kontrol panosu aracilığıyla ayarlanmaktadır. Sistemde, $13.5 \mathrm{~mm}$ çapında, $8160 \mathrm{~mm}$ uzunluğunda, $0.3459 \mathrm{~m}^{2}$ yüzey alanına sahip bakır borudan yapılı buharlaştırıcı ve $12 \mathrm{~mm}$ çapında, $16400 \mathrm{~mm}$ uzunluğunda, $0.6180 \mathrm{~m}^{2}$ yüzey alanına sahip bakır borudan yapılı yoğuşturucu kullanılmıştır.

\subsubsection{Suyla ön soğutma sistemi}

Genel görünümü Şekil 2(b)'de verilmiş olan suyla ön soğutma sistemi genel olarak; soğutma odası, 
su deposu, devir-daim su pompas1, su püskürtme sistemi, kontrol panosu ve içinde buharlaştırıcı, yoğuşturucu, kompresör, genleşme valfi ve soğutucu akışkan bulunan soğutma ünitesinden oluşmaktadır. Soğutma kabininin ölçüleri, hem soğutma kabininin hem de su deposunun etrafinı saran izolasyon malzemesi havayla ön soğutma sistemi ile aynı özelliklere sahiptir. Soğutma odasının tavanına, üzerinde 3 adet meme bulunan su püskürtme sistemi yerleştirilmiştir. Su deposu ana şasinin arka kısmında bulunmakta olup kalınlığ 2 mm olan paslanmaz çelik malzemeden, 980 x 780 x $700 \mathrm{~mm}$ boyutlarında ve $0.5351 \mathrm{~m}^{3}$ hacminde imal edilmiştir. Su deposunun içerisine $15 \mathrm{~mm}$ çapındaki sarmal borulardan oluşan biri 10 sarımlı diğeri 9 sarımlı bakır borudan yapılı iki adet 450 mm çapında bir serpantin şeklinde buharlaştırıcı yerleştirilmiştir. Serpantin şeklindeki buharlaştırıcı $17.5 \mathrm{~mm}$ çapında, $19.1 \mathrm{~m}$ uzunluğunda ve $1.05 \mathrm{~m}^{2}$ yüzey alanına sahiptir. Soğutucu kabinden tekrar sisteme dönen su, doğal akışıyla depoya geri dönmekte ve buradan tekrar sisteme $55 \mathrm{~W}$ gücünde bir devir-daim su pompası yardımıyla basılmaktadır. Sistemde; $10 \mathrm{~mm}$ çapında, $59.28 \mathrm{~m}$ uzunluğunda,
$1.8623 \mathrm{~m}^{2}$ yüzey alanına sahip bakır borudan yapılı hava soğutmalı yoğuşturucu bulunmaktadır.

\subsubsection{Vakumla ön soğutma sistemi}

Genel görünümü Şekil 1(c)'de verilmiş olan vakumla ön soğutma sistemi; vakum tank1, vakum pompası ve içinde buharlaştırıcı, yoğuşturucu, kompresör, genleşme valfi ve soğutucu akışkan bulunan soğutma ünitesinden oluşmaktadır. Vakum tankı $6 \mathrm{~mm}$ kalınlığında çelik sacdan, 0.6 $\mathrm{m}$ çapında ve $1 \mathrm{~m}$ uzunluğunda silindirik şekilde tasarlanmıştır. Soğutma tankının çevresine havayla soğutma sistemindeki ile aynı özelliklere sahip 1S1 yalıtım malzemesi kaplanmıştır. Vakumla ön soğutma sisteminde, soğutma tankının içine vakum pompasının etkinliğinin artırılması amacıyla, düşük basınçlarda ürün üzerinden buhar halinde uzaklaşan suyun tekrar sıvı hale gelerek ürüne dönmesini sağlayan $13.5 \mathrm{~mm}$ çapında $7350 \mathrm{~mm}$ uzunluğunda $0.3116 \mathrm{~m}^{2}$ yüzey alanına sahip bakır borudan yapılı buharlaştırıcı kullanılmıştır (Alibaş \& Okursoy 2009). Sistemde $11.8 \mathrm{~mm}$ çapında, $7.33 \mathrm{~m}$ uzunluğunda, $0.2716 \mathrm{~m}^{2}$ yüzey alanına sahip bakır borudan yapılı yoğuşturucu kullanılmıştır.

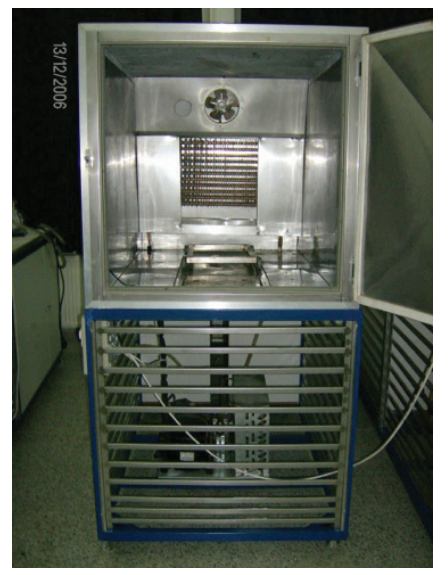

(a)

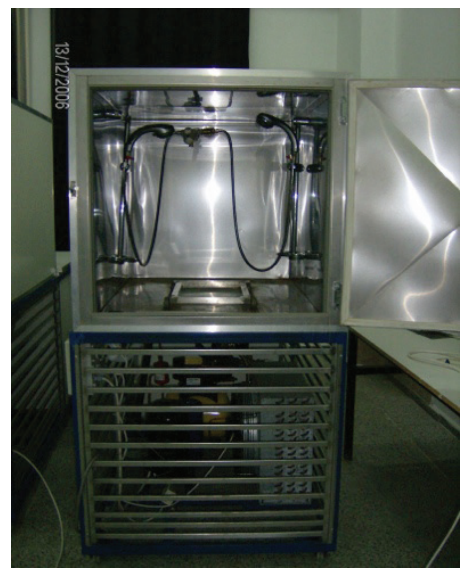

(b)

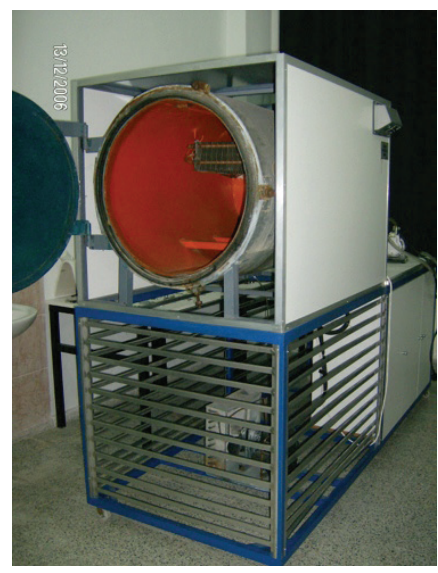

(c)

Şekil 1- Ön soğutma sistemlemleri; a, basınçlı havayla ön soğutma sistemi; b, suyla ön soğutma sistemi; c, vakumla ön soğutma sistemi

Figure 1-Pre-cooling systems; a, air-blast pre-cooling system; b, hydro pre-cooling system; c, vacuum precooling system

Tarım Bilimleri Dergisi - Journal of Agricultural Sciences 22 (2016) 480-491 
Vakumla soğutma sisteminde, döner hareketli ve yağlı tip bir vakum pompası kullanılmıştır. Vakum pompas1 (Carpanelli MMDE80B4, Italy) sistem basıncının $0.67 \mathrm{kPa}$ basınca kadar düşürülmesi amacıyla kullanılmaktadır.

\section{3. Ön soğutma yöntemleri}

Soğutulacak olan enginarlar $0.001 \mathrm{~kg}$ hassasiyetli bir terazi kullanılarak $5 \pm 0.005 \mathrm{~kg}$ (Baster-plus, LCB-2, Türkiye) olacak şekilde tartılarak plastik kasalara yerleştirilmişlerdir. Sıcaklık ölçümleri, hassasiyeti $0.1{ }^{\circ} \mathrm{C}$ olan bir veri toplama cihazı (Datalogger-10, Türkiye) aracılığıyla, 1 saniyede bir ölçüm alacak şekilde, sıcaklık ölçüm uçlarından (prob) ikisi kasanın merkezi, dördü kasanın sağ, sol ön ve arka yüzeyleri, ikisi kasanın alt ve üstü, diğer ikisi de soğutma kabininin içine olacak şekilde on kanaldan ölçüm alınması sağlanarak gerçekleştirilmiştir. Tüm soğutma işlemleri kasanın merkezine konulan iki sıcaklık ölçüm ucunun okuduğu değer $1{ }^{\circ} \mathrm{C}$ oluncaya dek gerçekleştirilmiştir (Zhang \& Sun 2006a; Zhang \& Sun 2006b).

Havayla ön soğutma sisteminde kullanılan fanın hiz1 $1 \mathrm{~m} \mathrm{~s}^{-1}$ (Dincer 1995; Teruel et al 2001; Wang \& Sun 2002a; Wang \& Sun 2002b), suyla ön soğutma sistemindeki debi ise $2.5 \mathrm{~L}_{\text {dakika }}{ }^{-1}$ olacak şekilde ayarlanmışlardır (Alibaş \& İzli 2013; Alibas \& Koksal 2014).

Vakumla ön soğutma sistemindeki basınç azalması analog (Viot 69044, US) ve civalı vakum metreler kullanılarak gerçekleştirilmiştir. Vakum tankının basıncı $0.67 \mathrm{kPa}$ değerine kadar düşürülebilmektedir.

Havayla ve vakumla ön soğutma sistemlerinin enerji tüketimleri tek fazlı (Kaan, 001, Türkiye), suyla ön soğutma sisteminin enerji tüketimi ise üç fazlı elektrik sayacı (Kaan, 002, Türkiye) ile gerçekleştirilmiştir.

\subsection{Kontrollü atmosfer odası (KAO) ve oda koşulları (OK)}

Ön soğutulmuş ürünlerin soğuk depolama sırasındaki dayanım süresinin ölçülmesi amacıyla sicaklığg $1{ }^{\circ} \mathrm{C}$, oransal nemi $\% 90 \pm 5$ ve atmosfer bileşimi ise 0:21 $\left[\left(\% \mathrm{CO}_{2}: \% \mathrm{O}_{2}\right)\right]$ olan bir kontrollü atmosfer odası (KAO) kullanılmıştır (Alibas \& Koksal 2015).

Ön soğutulmuş ürünlerin satış koşullarındaki dayanımlarının ölçülebilmesi için sıcaklığı $22 \pm 1$ ${ }^{\circ} \mathrm{C}$ ve oransal nemi \% 55-60 olan bir laboratuvar oda koşullarını (OK) temsil amacıyla kullanılmıştır (Akbudak \& Özer 2003; Alibas \& Koksal 2015).

\subsection{Kalite parametreleri}

\subsubsection{Sertlik ölçüm yöntemi}

Enginarın sertliği bir penetrometrenin (FT 327) 5/16"'lik ucuyla "N" cinsinden ölçülmüştür. Penetrometre bir taşıyıcı sehpa (Bosch BS 45) üzerine yerleştirilmiştir. Penetrometrenin üzerine yerleştirildiği sehpanın ölçüm alanına yerleştirilen enginar taçlarının üst kısmı penetrometre ucu ile temas ettirilerek penetrometre kolu ve uç vidası yardımıyla sıkıştırılmıştır. Böylece sertlik değerleri penetrometrenin kadranından okunmuştur. Her bir yöntem için on ayrı ölçümün ortalaması alınarak sertlik değeri belirlenmiştir (Alibas \& Koksal 2015). Ön soğutma yapılmamış enginarların 0. gündeki sertlik değerleri taze ürünün sertlik değerini vermiş ve bu değer kontrol değeri olarak kabul edilmiştir.

\subsubsection{Genel görünüm testi}

Tüm yöntemler için genel görünüm 0 . günde "10" olarak kabul edilmiş ve bu değer kontrol değeri olarak alınmıştır. Genel görünüm testi, uzman bitki fizyologlarından oluşan bir jüri tarafından gerçekleştirilmiştir. Genel görünüm testinde biyolojik materyal bir puanlama sistemi kullanılarak değerlendirilmiştir. Bu puanlama; 10-9: çok iyi, 8-7: iyi, 6-5: satılabilir, 4-3: satılamaz, 2-1: kullanılamaz şeklindedir (Özer \& Masatçı 2000; Özer 2002; Alibas \& Koksal 2015).

\subsubsection{Ağırlık kaybı ve bozulma oranı belirleme yöntemleri}

Tüm yöntemler için hem KAO hem de OK ağırlık kaybı 0 . günde $\% 0$ olarak kabul edilmiş ve bu değer kontrol değeri olarak alınmıştır. Ağırlıkları 1 $\mathrm{kg}$ olarak belirlenen enginarların, depolama süresi 
boyunca KAO'da her 15 günde bir ve $\mathrm{OK}$ 'da her 5 günde bir ağırlık kaybı değerleri belirlenmiştir (Özer \& Masatç1 2000; Alibaş \& Okursoy 2009).

Tüm yöntemler için bozulma oranı 0 . günde $\% 0$ olarak kabul edilmiş ve bu değer kontrol değeri olarak alınmıştır. Bozulma oranının belirlenmesi genel görünüm, sertlik ve ağırlık kaybı değerlerinin hepsine birden bakılarak yapılmıştır (Alibaş \& Okursoy 2012).

\subsection{Verilerin analizi}

Çalışma 3 tekerrürlü olarak kurulmuştur. Elde edilen verilerin ortalamaları ve diğer istatistik değerleri MINITAB 13 aracılığıyla saptanmış ve sonuçlar LSD testine $(\mathrm{P}<0.01)$ göre MSTATC istatistik programı kullanılarak harflendirilmiştir.

Veri toplama cihazı aracılığıyla ölçülen zamana bağlı sıcaklık değerleri doğrusal olmayan regresyon analizi yapan NLREG (NLREG 6.3) programı (Eşitlik 1) aracılığıyla tahminlenmiştir. Doğrusal olmayan regresyon analizinin sonuçları soğutma katsayısını $\left(K_{s}\right)$, tahminin standart hatasinı $(S H)$ ve regresyon modeli karar katsayısını $\left(R^{2}\right)$ vermektedir (Alibaş \& Okursoy 2009; Alibaş \& Okursoy 2012; Alibaş \& İzli 2013; Alibas \& Koksal 2014).

$$
T=T_{i}+\left[T_{m} x \exp \left(K_{s} x t\right)\right]
$$

Burada; $T$, veri toplama cihazı aracılığıyla ölçülen sıcaklık değeri $\left({ }^{\circ} \mathrm{C}\right) ; T_{i}$, ürünün ön soğutma işlemi sonunda ulaşması istenen sıcaklık değeri $\left({ }^{\circ} \mathrm{C}\right) ; T_{m}$, materyalin soğutulmadan önceki sıcaklığ 1 $\left({ }^{\circ} \mathrm{C}\right) ; K_{s}$, soğutma katsayısı (birimsiz) ve $t$, soğutma süresi (s)'dir.

\section{Bulgular ve Tartışma}

\section{1. Ön soğutma parametrelerinin belirlenmesi}

Enginarın havayla, vakumla ve suyla ön soğutulmasına ilişkin zamana bağlı sıcaklık azalması Şekil 2'de verilmiştir. Şekil 2'ye göre, en kısa süreli soğutma işleminin 35 dakika ile vakumla ön soğutma yöntemi, en uzun yöntemin ise 135 dakika ile havayla ön soğutma yöntemi olduğu saptanmıştır. Buna göre vakumla ön soğutma yönteminin, havayla ön soğutma yöntemine göre 3.86 kat daha hılı ön soğutma yapılabildiği belirlenmiştir. Enginarın suyla ön soğutulması ise 81 dakika sürmüştür. Suyla ön soğutma yöntemlerinde belirlenen soğutma süresinin vakumla ön soğutma yönteminde belirlenen soğutma süresine göre 2.31 kat arttığı; havayla ön soğutma yönteminde belirlenen soğutma süresine göre ise 1.67 kat azaldığı tespit edilmiştir. Benzer sonuçlar, çeşitli araştırıcılar tarafından da ifade edilmiştir (Sun \& Wang 2004; Cheng 2006; Zhang \& Sun 2006b; Jackman et al 2007; Alibaş \& Okursoy 2009; Alibaş \& Okursoy 2012; Alibas \& Koksal 2014).

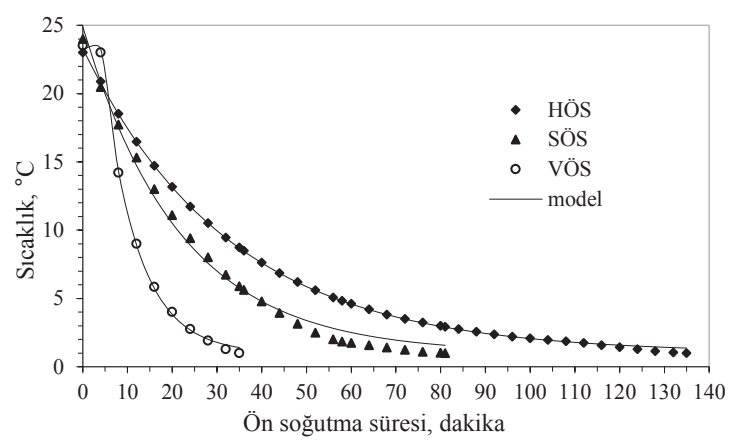

Şekil 2- Enginarın vakumla, havayla ve suyla soğutulmasındaki zamana bağlı sıcaklık eğrileri

Figure 2- The temperature curves depending on precooling time during vacuum, air and hydro pre-cooling of artichokes

Enginarın havayla, vakumla ve suyla ön soğutulması sirasında elde edilen istatistiki veriler Çizelge 1'de verilmiştir. Ön soğutma denemelerinden elde edilen veriler ile soğutma modelinin belirlediği veriler arasındaki karar katsayısının $\left(R^{2}\right)$ en yüksek olduğu ön soğutma yönteminin 0.9996 değeri ile havayla ön soğutma yöntemi olduğu tespit edilmiştir. Bunu sırasıyla 0.9991 değeri ile vakumla ve 0.9930 değeri ile suyla ön soğutma yöntemleri izlemiştir.

Enginarın vakumla ön soğutulması sirasında ölçülen sıcaklık, basınç ve zaman arasındaki ilişkiler Şekil 3'de verilmiştir. Toplam 35 dakika süren vakumla soğutma işleminin 4. dakikasında basınç $2.93 \mathrm{kPa}$ değerine ulaşmış ve bu noktada üründe 
Çizelge 1- Havayla, suyla ve vakumla ön soğutma yöntemlerinin ön soğutma verileri

Table 1- The statistical data of air, hydro and vacuum pre-cooling methods

\begin{tabular}{|c|c|c|c|}
\hline $\begin{array}{l}\text { Ön soğutma } \\
\text { yöntemi }\end{array}$ & $\begin{array}{l}\text { Tahminin standart } \\
\text { hatasl }(\mathrm{SH})^{* *}\end{array}$ & $\begin{array}{c}\text { Regresyon modeli karar } \\
\text { katsaylsi }\left(R^{2}\right)^{* *}\end{array}$ & $\begin{array}{l}\text { Soğutma katsayıs } \\
\qquad(K)^{* *}\end{array}$ \\
\hline HÖS & $0.120816^{\mathrm{b}^{*}}$ & $0.9996^{\mathrm{a}}$ & $0.0304295648^{c}$ \\
\hline VÖS & $0.191241^{\mathrm{b}}$ & $0.9991^{\mathrm{a}}$ & $0.1288981560^{\mathrm{a}}$ \\
\hline SÖS & $0.563272^{\mathrm{a}}$ & $0.9930^{\mathrm{b}}$ & $0.0460402651^{\mathrm{b}}$ \\
\hline
\end{tabular}

*, aynı sütunda farklı harflerle gösterilen ortalamalar arası fark önemlidir; **, $\mathrm{P}<0.01$

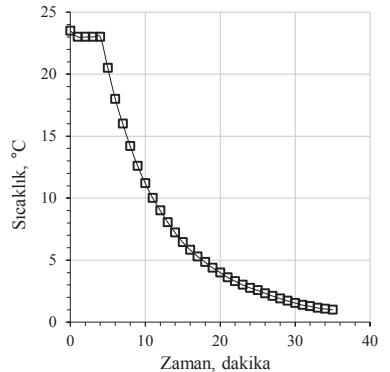

(a)

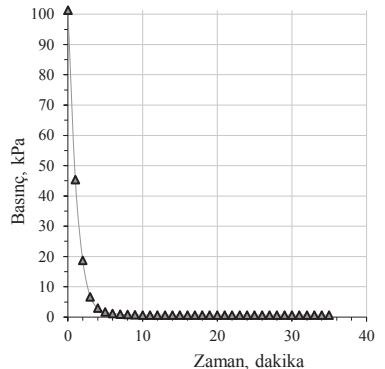

(b)

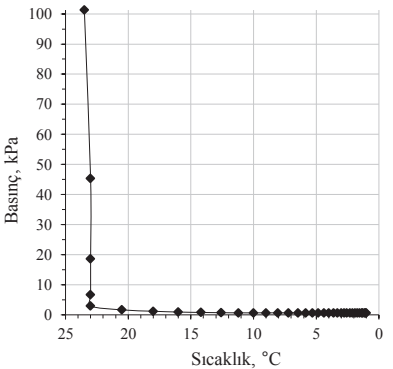

(c)

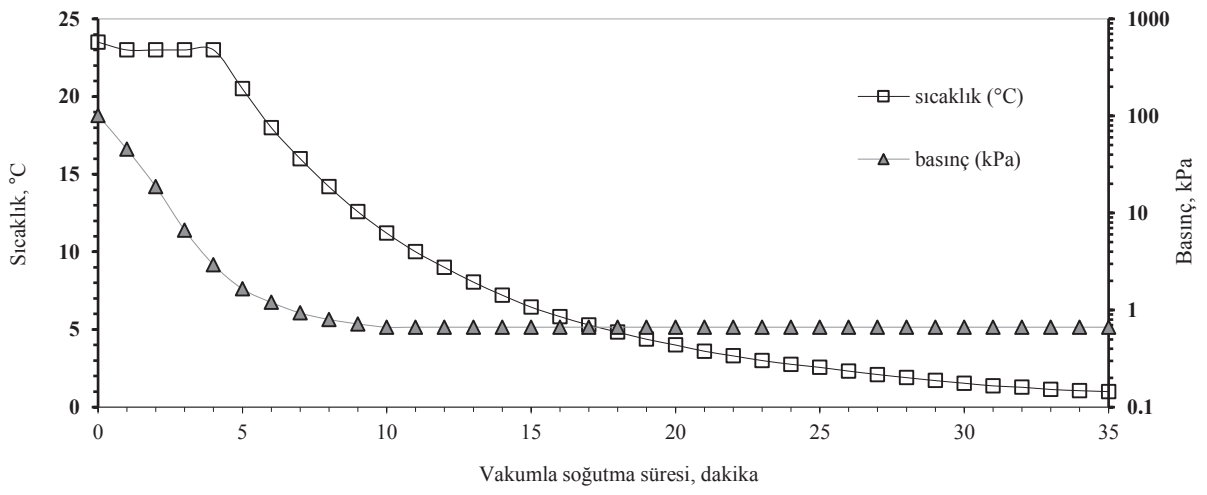

(d)

Şekil 3- Enginarın vakumla ön soğutulmasındaki a, sıcaklık-zaman; b, basınç-zaman; c, basınç-sıcaklık; d, basınç-sıcaklık-zaman grafikleri

Figure 3- The diagrams of vacuum precooling of artichoke a, temperature-precooling time; $b$, pressure-precooling time; c, pressure-temperature and $d$, pressure-temperature-precooling time

maksimum düzeyde buharlaşma meydana gelmiştir. Dördüncü dakikaya kadar sabit kalan sıcaklık, parlama noktası adı verilen bu andan sonra hızlı bir şekilde düşmeye başlamıştır. Sistem minimum basınç değeri olan $0.67 \mathrm{kPa}$ basınca 10 dakikada ulaşmış olup bu basinç değeri vakumla ön soğutma işleminin sonuna kadar sabit kalmıştır.

Enginarın çeşitli yöntemlerle ön soğutulmasındaki enerji tüketimi, güç ve ağırlık farkı değerleri Çizelge 2 'de verilmiştir. Enginarın ön soğutulmasındaki en 
yüksek enerji tüketimi $0.84 \mathrm{kWh}$ değeri ile havayla ön soğutma yönteminde ölçülmüştür. Bunu sirasıyla $0.65 \mathrm{kWh}$ ve $0.38 \mathrm{kWh}$ değerleri ile suyla ve vakumla ön soğutma yöntemleri takip etmiştir. Enerji tüketimi açısından en pahalı yöntem olan havayla ön soğutma yöntemindeki enerji tüketiminin, en ekonomik yöntem olan vakumla ön soğutma yöntemine göre 2.21 kat fazla olduğu belirlenmiştir. En fazla güç gereksinimi ise 0.6514 $\mathrm{kW}$ değeri ile vakumla ön soğutma yönteminde meydana gelmiştir. Bunu sırasıyla $0.4815 \mathrm{~kW}$ değeri ile suyla ve $0.3733 \mathrm{~kW}$ değeri ile havayla ön soğutma yöntemleri takip etmiştir. En fazla gücün harcandığı vakumla ön soğutma yöntemindeki güç gereksiniminin, havayla ön soğutma yöntemindeki güç gereksinimine göre 1.75 kat fazla olduğu saptanmıştır. Enerji ve güç tüketimi ile ilgili benzer sonuçlar literatür çalışmaları ile paralellik göstermektedir (Alibaş \& Okursoy 2012; Alibas \& Koksal 2014). Ön soğutma işlemlerinin sonunda suyla ön soğutulmuş ürünlerde $\% 2.83$ değerinde bir ağırlık artışı, havayla ve vakumla ön soğutulmuş enginarlarda ise sırasıyla \% 1.03 ve $\% 1.88$ değerinde bir ağırlık kaybı saptanmıştır. Haas \& Gur (1987) vakumla soğutma sirasinda meydana gelen her 5-6 ${ }^{\circ} \mathrm{C}$ 'lik sıcaklık düşüşünün marulun bünyesinde yaklaşık \% 1'lik bir ağırlık kaybına neden olduğunu belirlemişlerdir. Ağırlık artış ve azalışlarına ilişkin benzer sonuçlar, çeşitli araştırıcılar tarafından ifade edilmiştir (Desmond et al 2000; McDonald et al 2000; Desmond et al 2002; McDonald et al 2002; Jackman et al 2007; Alibaş \& Okursoy 2009; Alibaş \& Okursoy 2012; Alibas \& Koksal 2014).

\subsection{Kalite parametrelerinin belirlenmesi}

\subsubsection{KAO muhafaza sirasindaki kalite parametrelerinin belirlenmesi}

Havayla, vakumla ve suyla ön soğutulmuş enginarlar ile kontrol kabul edilen ön soğutulmamış enginarların kontrollü atmosfer odasında $0 ., 15$. ve 30. günlerde belirlenmiş sertlik, genel görünüm, bozulma oranı ve ağırlık kaybı değerleri Çizelge 3'de verilmiştir.

Tüm soğutma yöntemleri içinde 30 . günde en az bozulma \% 25 değeri ile havayla ön soğutma yönteminde meydana gelmiştir. Bunu sırasıyla \% 30 değeri ile vakumla ön soğutma, \% 38 değeri ile kontrol koşulları ve \% 55 değeri ile suyla ön soğutma yöntemi izlemiştir. Kontrol koşullarında depolanan enginarlarda oluşan bozulma oranının, havayla ön soğutulan enginarlarda oluşan bozulma oranına göre $130 \mathrm{~kg} \mathrm{t}^{-1}$ ürün kaybına; suyla ön soğutulan enginarlara göre ise $170 \mathrm{~kg} \mathrm{t}^{-1}$ ürün kazancına neden olduğu tespit edilmiştir.

Kontrollü atmosfer odasında 30. günün sonunda ağırlık kaybı değeri açısından en az kayba neden olan yöntemin \% 12 değeri ile havayla ön soğutma yöntemi olduğu saptanmıştır. Bu değeri \% 13 değeri ile vakumla, \% 15 değeri ile kontrol koşulları ve $\% 18.5$ değeri ile suyla ön soğutma yönteminin takip ettiği tespit edilmiştir. Kontrol şartlarında KAO'da muhafaza edilmiş enginarlarda 30 . günde ölçülen ağırlık kaybı değerinin suyla ön soğutulan enginarlara göre \% 23 oranında daha az olduğu belirlenmiştir.

Vakumla ve havayla ön soğutularak kontrollü atmosfer odasına konulan enginarların 30 . günün sonundaki genel görünüm derecesi sırasıyla " 7 "

\section{Çizelge 2- Enginarın ön soğutma parametreleri}

Table 2- The pre-cooling parameters of artichokes

\begin{tabular}{|c|c|c|c|c|}
\hline $\begin{array}{l}\text { Ön soğutma } \\
\text { yöntemi }\end{array}$ & $\begin{array}{c}\text { Soğutma süresi }{ }^{* *} \\
(\text { dakika })\end{array}$ & $\begin{array}{c}\text { Enerji tüketimi }{ }^{* *} \\
(\mathrm{kWh})\end{array}$ & $\begin{array}{l}G \ddot{u} c^{* *} \\
(k W)\end{array}$ & 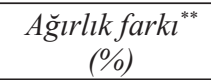 \\
\hline HÖS & $135 \pm(5.030)^{\mathrm{a}^{*}}$ & $0.84 \pm(0.0252)^{\mathrm{a}}$ & $0.3733 \pm(0.00299)^{\mathrm{c}}$ & $-1.03 \pm(0.0321)^{c}$ \\
\hline VÖS & $35 \pm(1.530)^{\mathrm{c}}$ & $0.38 \pm(0.0208)^{\mathrm{c}}$ & $0.6514 \pm(0.00218)^{\mathrm{a}}$ & $-1.88 \pm(0.0451)^{b}$ \\
\hline SÖS & $81 \pm(2.520)^{\mathrm{b}}$ & $0.65 \pm(0.0265)^{\mathrm{b}}$ & $0.4815 \pm(0.00414)^{\mathrm{b}}$ & $2.83 \pm(0.0306)^{\mathrm{a}}$ \\
\hline
\end{tabular}

*, aynı sütunda farklı harflerle gösterilen ortalamalar arası fark önemlidir; **, $\mathrm{P}<0.01$ 


\section{Çizelge 3- Enginarın kontrollü atmosferde (KA) soğuk depolanması sırasındaki kalite parametreleri}

Table 3- The quality parameters of artichoke during cold storage in modified atmosphere room (MA)

\begin{tabular}{|c|c|c|c|c|c|}
\hline $\begin{array}{l}\text { Ön soğutma } \\
\text { yöntemi }\end{array}$ & $\begin{array}{c}\text { Depolama süresi } \\
\text { (gün) }\end{array}$ & $\begin{array}{l}\text { Sertlik }^{* *} \\
\quad(N)\end{array}$ & $\begin{array}{c}A \breve{g l r l} \imath k k a y b \imath^{* *} \\
(\%)\end{array}$ & $\begin{array}{c}\text { Bozulma orant } \\
(\%)\end{array}$ & $\begin{array}{c}\text { Genel görünüm }^{* * *} \\
(1-10)\end{array}$ \\
\hline \multirow{3}{*}{ ÖS } & 0 & $48.66 \pm(0.118)^{a^{*}}$ & $0.000 \pm(0.000)^{\mathrm{d}}$ & $0.000 \pm(0.000)^{\mathrm{g}}$ & $10.000 \pm(0.000)^{\mathrm{a}}$ \\
\hline & 15 & $37.80 \pm(0.147)^{\mathrm{g}}$ & $6.000 \pm(1.530)^{\mathrm{c}}$ & $10.000 \pm(2.520)^{\mathrm{e}}$ & $9.000 \pm(0.289)^{\mathrm{b}}$ \\
\hline & 30 & $23.15 \pm(0.206)^{\mathrm{k}}$ & $15.000 \pm(1.730)^{\mathrm{b}}$ & $38.000 \pm(1.530)^{\mathrm{b}}$ & $6.000 \pm(0.577)^{\mathrm{e}}$ \\
\hline \multirow{3}{*}{ HÖS } & 0 & $48.07 \pm(0.118)^{b}$ & $0.000 \pm(0.000)^{\mathrm{d}}$ & $0.000 \pm(0.000)^{\mathrm{g}}$ & $10.000 \pm(0.000)^{\mathrm{a}}$ \\
\hline & 15 & $41.96 \pm(0.147)^{\mathrm{d}}$ & $4.000 \pm(0.577)^{\mathrm{c}}$ & $3.000 \pm(1.000)^{\mathrm{fg}}$ & $10.000 \pm(0.000)^{\mathrm{a}}$ \\
\hline & 30 & $27.37 \pm(0.206)^{\mathrm{i}}$ & $12.000 \pm(1.530)^{\mathrm{b}}$ & $25.000 \pm(3.610)^{\mathrm{c}}$ & $8.000 \pm(0.577)^{c}$ \\
\hline \multirow{3}{*}{ VÖS } & 0 & $46.99 \pm(0.353)^{c}$ & $0.000 \pm(0.000)^{\mathrm{d}}$ & $0.000 \pm(0.000)^{g}$ & $10.000 \pm(0.000)^{\mathrm{a}}$ \\
\hline & 15 & $39.24 \pm(0.265)^{\mathrm{f}}$ & $4.500 \pm(1.040)^{\mathrm{c}}$ & $7.000 \pm(1.530)^{\mathrm{ef}}$ & $10.000 \pm(0.000)^{\mathrm{a}}$ \\
\hline & 30 & $25.21 \pm(0.353)^{\mathrm{j}}$ & $13.000 \pm(1.730)^{\mathrm{b}}$ & $30.000 \pm(3.210)^{\mathrm{c}}$ & $7.000 \pm(0.289)^{\mathrm{d}}$ \\
\hline \multirow{3}{*}{ SÖS } & 0 & $40.19 \pm(0.088)^{\mathrm{e}}$ & $0.000 \pm(0.000)^{\mathrm{d}}$ & $0.000 \pm(0.000)^{\mathrm{g}}$ & $10.000 \pm(0.000)^{\mathrm{a}}$ \\
\hline & 15 & $33.48 \pm(0.196)^{\mathrm{h}}$ & $7.000 \pm(1.530)^{\mathrm{c}}$ & $18.000 \pm(1.530)^{\mathrm{d}}$ & $9.000 \pm(0.289)^{\mathrm{b}}$ \\
\hline & 30 & $19.94 \pm(0.118)^{1}$ & $18.500 \pm(1.260)^{\mathrm{a}}$ & $55.000 \pm(2.890)^{\mathrm{a}}$ & $5.000 \pm(0.000)^{\mathrm{f}}$ \\
\hline
\end{tabular}

*, aynı sütundaki farklı harflerle gösterilen ortalamalar arası fark önemlidir; **, $\mathrm{P}<0.01$

ve "8" puan ile "iyi", kontrol şartlarında ve suyla ön soğutularak muhafaza edilen enginarların genel görünüm derecesi ise sirasiyla " 6 " ve " 5 " puan ile "satılabilir" olarak derecelendirilmiştir.

Taze enginarın sertlik değeri (ön soğutulmamış, 0. gün) $48.66 \mathrm{~N}$ olarak saptanmıştır. Havayla, suyla ve vakumla ön soğutulmuş enginarların KAO öncesi ölçülen sertlik değerleri ise sırasıyla 48.07, 40.19 ve $46.99 \mathrm{~N}$ olarak belirlenmiştir. KAO’da 30. gün sonundaki sertlik değerleri içinde taze ürüne en yakın sertlik değeri $27.37 \mathrm{~N}$ değeri ile havayla ön soğutma yönteminde bulunmuştur. Bunu sırasıyla $25.51 \mathrm{~N}$ değeri ile vakumla ön soğutma, $23.15 \mathrm{~N}$ değeri ile kontrol koşulları ve $19.94 \mathrm{~N}$ değeri ile suyla ön soğutma yöntemleri izlemiştir. Ön soğutma yapılmamış enginarlarda 30. gün sonunda ölçülen sertlik değerinin, suyla ön soğutma yöntemlerinde saptanan sertlik değerinden $\% 16.1$ oranında daha fazla olduğu saptanmıştır. Suyla ön soğutma yöntemi enginarların soğuk depolanması sürecinde sertliklerinin azalmasına neden olmuştur.

\subsubsection{OK muhafaza sirasindaki kalite parametrelerinin belirlenmesi}

Havayla, suyla ve vakumla ön soğutma yöntemleri ile soğutulmuş enginarlar ile kontrol koşullarına sahip enginarların pazar koşullarında dayanımlarının belirlenmesi açısından nemi ve sıcaklığı sabit olan oda koşullarında (OK) bekletilmesi sonucu 0., 5. ve 10. günlerde ölçülen sertlik, genel görünüm, bozulma oranı ve ağırlık kaybı değerleri Çizelge 4'de verilmiştir.

Havayla, vakumla ve suyla ön soğutma yapılmış enginarlar ile kontrol koşullarındaki enginarların OK'da10günboyuncabekletilmelerisonucusaptanan bozulma oranı değerlerine göre en az bozulma \% 7 değeri ile havayla ön soğutma yönteminde meydana gelmiştir. Havayla ön soğutma yöntemini sırasıyla \% 13 değeri ile vakumla ön soğutma yöntemi, $\% 25$ değeri ile kontrol koşulları ve \% 31 değeri ile suyla ön soğutma yöntemi izlemiştir. Ön soğutma yapılmamış ürünlerde saptanan bozulma oranının suyla ön soğutulmuş enginarlarda gözlenen bozulma oranından \% 24 daha az olduğu tespit edilmiştir. OK'da 10. günde ön soğutma yapılmamış ürünlerde saptanan bozulma oranının havayla ön soğutulmuş enginarlarda saptanan bozulma oranından 3.57 kat fazla olduğu saptanmıştır. Meydana gelen ağırlık kaybı değerlerinden yola çıkılarak bir ton $(1000 \mathrm{~kg})$ ürün başına bozulan ürün miktarı hesaplandığında, ön soğutulmadan satışa çıkarılmış ürünlerde 10 . günün sonunda $250 \mathrm{~kg}$ ürünün bozularak atıldığ 1 
Çizelge 4- Enginarın oda koşullarında (OK) depolanması sırasındaki kalite parametreleri

Table 4- The quality parameters of artichoke during storage in room conditions (RC)

\begin{tabular}{lccccc}
\hline $\begin{array}{l}\text { Ön soğutma } \\
\text { yöntemi }\end{array}$ & $\begin{array}{c}\text { Depolama süresi } \\
\text { (gün) }\end{array}$ & $\begin{array}{c}\text { Sertlik } k^{* *} \\
(N)\end{array}$ & $\begin{array}{c}\text { Ăgrlik kaybi }^{* *} \\
(\%)\end{array}$ & $\begin{array}{c}\text { Bozulma orant }^{* *} \\
(\%)\end{array}$ & $\begin{array}{c}\text { Genel görünüm }^{* *} \\
(1-10)\end{array}$ \\
\hline \multirow{3}{*}{ ÖS } & 0 & $48.66 \pm(0.118)^{\mathrm{a}}$ & $0.000 \pm(0.000)^{\mathrm{g}}$ & $0.000 \pm(0.000)^{\mathrm{h}}$ & $10.000 \pm(0.000)^{\mathrm{a}}$ \\
& 15 & $37.25 \pm(0.147)^{\mathrm{g}}$ & $23.500 \pm(0.764)^{\mathrm{e}}$ & $7.000 \pm(1.530)^{\mathrm{e}}$ & $7.000 \pm(0.577)^{\mathrm{ef}}$ \\
HÖS & 30 & $20.41 \pm(0.118)^{\mathrm{k}}$ & $39.000 \pm(2.520)^{\mathrm{a}}$ & $25.000 \pm(2.890)^{\mathrm{b}}$ & $4.333 \pm(0.441)^{\mathrm{g}}$ \\
\hline \multirow{3}{*}{ VÖS } & 0 & $48.07 \pm(0.118)^{\mathrm{b}}$ & $0.000 \pm(0.000)^{\mathrm{g}}$ & $0.000 \pm(0.000)^{\mathrm{h}}$ & $10.000 \pm(0.000)^{\mathrm{a}}$ \\
& 15 & $42.02 \pm(0.147)^{\mathrm{d}}$ & $15.500 \pm(2.470)^{\mathrm{f}}$ & $2.000 \pm(1.000)^{\mathrm{g}}$ & $9.000 \pm(0.000)^{\mathrm{ab}}$ \\
& 30 & $36.07 \pm(0.147)^{\mathrm{h}}$ & $31.500 \pm(1.760)^{\mathrm{c}}$ & $7.000 \pm(1.530)^{\mathrm{e}}$ & $7.000 \pm(0.577)^{\mathrm{cd}}$ \\
\hline \multirow{3}{*}{ SÖS } & 0 & $46.99 \pm(0.353)^{\mathrm{c}}$ & $0.000 \pm(0.000)^{\mathrm{g}}$ & $0.000 \pm(0.000)^{\mathrm{h}}$ & $10.000 \pm(0.000)^{\mathrm{a}}$ \\
& 15 & $40.71 \pm(0.167)^{\mathrm{e}}$ & $17.000 \pm(2.000)^{\mathrm{f}}$ & $4.000 \pm(1.000)^{\mathrm{f}}$ & $8.000 \pm(0.577)^{\mathrm{bc}}$ \\
& 30 & $30.19 \pm(0.147)^{\mathrm{j}}$ & $34.500 \pm(2.470)^{\mathrm{b}}$ & $13.000 \pm(2.520)^{\mathrm{d}}$ & $6.000 \pm(0.289)^{\mathrm{de}}$ \\
\hline
\end{tabular}

*, aynı sütundaki farklı harflerle gösterilen ortalamalar arası fark önemlidir; **, $\mathrm{P}<0.01$

saptanmıştır. Ancak havayla ön soğutulduktan sonra pazara çıkarılan enginarlarda bu kaybın 70 $\mathrm{kg}$ olduğu belirlenmiştir. İşlem görmeden pazara çıkarılan enginarlara göre, havayla ön soğutulan enginarlarda 10. günde saptanan bozulma oranı ile bir ton üründe $180 \mathrm{~kg}$ ürün kazancı sağlandığı tespit edilmiştir. Suyla ön soğutularak OK'da 10 gün boyunca bekletilen bir ton üründe meydana gelen bozulma oranı ise $310 \mathrm{~kg}$ olarak belirlenmiştir. Suyla ön soğutularak pazar koşullarında satışa çıkarılmış bir ton enginarda 10. günde meydana gelen bozulmanın, hiç ön soğutma yapılmadan pazara çıkarılmış enginarlarda saptanan bozulma oranından $60 \mathrm{~kg}$ fazla olduğu saptanmıştır.

Çalışmada, en az ağırlık kaybına neden olan yöntemin \% 31.5 değeri ile havayla ön soğutma yöntemi olduğu; bunu sirasılyla \% $34.5, \% 39$ ve $\% 40.5$ değerleri ile vakumla, kontrol şartları ve suyla ön soğutma yöntemlerinin izlediği belirlenmiştir.

Havayla ön soğutma yöntemi uygulanarak ön soğutulmuş enginarlar 10. günün sonunda " 7 " puan ile genel görünüm açısından "iyi"; vakumla ön soğutulmuş enginarlar ise " 6 " puan ile "satılabilir" olarak değerlendirilmiştir. Ön soğutma yapılmamış enginarlar ile suyla ön soğutulmuş enginarların 10 gün sonundaki genel görünüm derecesi ise sirasıyla "4" ve "3" puan ile "satılamaz" olarak değerlendirilmiştir.

Oda koşullarında 10. gün sonundaki sertlik değerleri içinde taze ürüne en yakın sertlik değerinin $36.07 \mathrm{~N}$ değeri ile havayla ön soğutma yöntemi olduğu belirlenmiştir. Havayla ön soğutma yöntemini sırasılyla $30.19 \mathrm{~N}$ değeri ile vakumla, $20.41 \mathrm{~N}$ değeri ile kontrol koşulları ve $19.20 \mathrm{~N}$ değeri ile suyla ön soğutma yöntemleri izlemiştir. Ön soğutma yapılmamış enginarlarda 10. gün sonunda ölçülen sertlik değerinin, suyla ön soğutma yöntemine göre \% 6.3 oranında fazla olduğu tespit edilmiştir.

\section{Sonuçlar}

Bu çalışmada, enginar havayla, vakumla ve suyla ön soğutulmuştur. Soğutma süresinin en kısa, enerji tüketiminin ise en düşük olduğu soğutma yönteminin vakumla ön soğutma yöntemi olduğu saptanmıştır. Hem enerji tüketimi hem de soğutma süresi açısından vakumla ön soğutma yöntemini sırasıyla suyla ve havayla ön soğutma yöntemlerinin izlediği belirlenmiştir. Suyla ön soğutulan materyallerde soğutma işlemi sırasında ağırlık artışı, havayla ve vakumla ön soğutulmuş materyallerde ise ağırlık kaybı oluştuğu tespit edilmiştir. Ayrıca en fazla güç 
gereksiniminin vakumla ön soğutma yönteminde meydana geldiği, bunu sırasıyla suyla ve havayla ön soğutma yöntemlerinin izlediği saptanmıştır.

Enginarın oda ve kontrollü atmosfer koşullarında muhafaza edilmesinde kalite parametreleri açısından en uygun soğutma yönteminin havayla ön soğutma yöntemi olduğu, bunu sirasiyla vakumla, kontrol şartları ve suyla ön soğutma yönteminin izlediği belirlenmiştir. Ön soğutulmaksızın oda ve kontrollü atmosfer koşullarında depolanan enginarın kalite parametrelerinin, suyla ön soğutulmuş enginarlara göre daha yüksek olduğu saptanmıştır. Buna bağlı olarak bu çalışmada, enginarı suyla ön soğutmanın önemli ölçüde kalite kaybına neden olduğu belirlenmiştir.

\begin{tabular}{|ll|}
\hline \multicolumn{2}{|l|}{ Kısaltmalar ve Semboller } \\
\hline HÖS & Havayla ön soğutma \\
KAO & Kontrollü atmosfer odası \\
$\mathrm{S}_{\mathrm{s}}$ & Soğutma katsayısı \\
LSD & En küçük anlamlı fark \\
$\mathrm{OK}$ & Oda koşulları \\
$\mathrm{R}^{2}$ & Regresyon modeli karar katsayısı \\
$\mathrm{SH}$ & Standart hata \\
$\mathrm{SÖS}$ & Suyla ön soğutma \\
VÖS & Vakumla ön soğutma \\
$T$ & Veri toplama cihazı aracılı̆̆ıyla ölçülen \\
& sicaklık \\
$T_{i}$ & Ürünün ön soğutma işlemi sonunda \\
& ulaşmasi istenen sıcaklık \\
$T_{m}$ & Materyalin hasat sıcaklığı \\
$t$ & Ön soğutma süresi \\
\hline
\end{tabular}

\section{Kaynaklar}

Akbudak B \& Özer M H (2003). Farklı sicaklıklarda muhafaza edilen turşuluk hıyarda meydana gelen fiziksel ve kimyasal değişimler. Uludağ Üniversitesi Ziraat Fakültesi Dergisi 17(1): 33-46

Alibaş İ (2012). Asma yaprağının (Vitis vinifera L.) mikrodalga enerjisiyle kurutulması ve bazı kalite parametrelerinin belirlenmesi. Tarım Bilimleri Dergisi-Journal of Agricultural Sciences 18(1): 43-53
Alibaş İ \& Okursoy R (2009). Determination of operating and quality parameters during air blast, vacuum and hydro pre-cooling of spinach. Tarım Makinalart Bilimi Dergisi 5(2): 149-160

Alibaş İ \& Okursoy R (2012). A comparison study of some operating parameters during vaccum, air and hydro pre-cooling of faba beans, and determination of the quality parameters during storage period. Tarım Makinalart Bilimi Dergisi 8(2): 185-197

Alibaş İ \& İzli N (2013). Determination of the storage and quality parameters of nettle leaves hydro precooleding different water temperatures. Tarım Makinaları Bilimi Dergisi 9(1): 21-27

Alibas I \& Koksal N (2014). Forced-air, vacuum and hydro precooling of cauliflower (Brassica oleracea $\mathrm{L}$. var. botrytis cv. Freemont): Part I. Determination of precooling parameters. Food Science and Technology 34(4): 730-737

Alibas I \& Koksal N (2015). Forced-air, vacuum and hydro precooling of cauliflower (Brassica oleracea $\mathrm{L}$. var. botrytis cv. Freemont): Part II. Determination of quality parameters during storage. Food Science and Technology 35(1): 45-50

Brosnan T \& Sun D W (2003). Influence of modulated vacuum cooling on the cooling rate, mass loss and vase life of cut lily flowers. Biosystems Engineering 86(1): 45-49

Cheng H P (2006). Vacuum cooling combined with hydrocooling and vacuum drying on bamboo shoots. Applied Thermal Engineering 26: 2168-2175

Desmond E M, Kenny T A \& Ward P (2000). Effect of rapid and conventional cooling methods on the quality of cooked ham joints. Meat Science 56: 271-277

Desmond E M, Kenny T A \& Ward P (2002). The effect of injection level and cooling method on the quality of cooked ham joints. Meat Science 60(3): 271-277

Dincer I (1995). Air flow precooling of individual grapes. Journal of Food Engineering 6(2): 243-249

Dostal M \& Petera K (2004). Vacuum cooling of liquids: Mathematical model. Journal of Food Engineering 61(4): 533-539

Günhan T, Demir V \& Yağcığlu A (2014). Mathematical modelling of convection drying characteristics of artichoke (Cynara Scolymus L.) leaves. Tarm Bilimleri Dergisi-Journal of Agricultural Sciences 20(4): 415-426 
Haas E \& Gur G (1987). Factor affecting the cooling rate of lettuce in vacuum cooling installations. International Journal of Refrigeration 10(2): 82-86

Houska M, Sun D-W, Landfeld A \& Zhihang Z (2003). Experimental study of vacuum cooling of cooked beef in soup. Journal of Food Engineering 59(2-3): 105110

Jackman P, Sun D W \& Zheng L (2007). Effect of combined vacuum cooling and air blast cooling on time and cooling loss of large cooked beef joints. Journal of Food Engineering 81: 266-271

McDonald K \& Sun D W (2000). Vacuum cooling technology for the food processing industry: A review. Journal of Food Engineering 45(2): 55-65

McDonald K, Sun D W \& Kenny T (2000). Comparison of the quality of cooked beef products cooled by vacuum cooling and by conventional cooling. LebensmittelWissenschaft Und-Technologie 33(1): 21-29

McDonald K, Sun D W \& Lygn J G (2002). Effect of vacuum cooling on the thermophysical properties of a cooked beef product. Journal of Food Engineering 52(2): 167-176

Özer M H (2002). Jonagold elma çeşidinin kontrollü atmosferde muhafazası. Uludă̆ Üniversitesi Ziraat Fakültesi Dergisi 16(2): 189-202

Özer M H \& Masatçı F (2000). Domatesin kontrollü atmosferde (KA) muhafazası üzerine bir araştırma. Uludă̆ Üniversitesi Ziraat Fakültesi Dergisi 14: 4557

Romani A, Pinelli P, Cantani C, Cimato A \& Heimler D (2006). Characterization of violetto di toscana, a typical italian variety of artichoke (Cynara scolymus L.). Food Chemistry 95(2): 221-225

Sankat C K \& Mujaffar S (1999). Water balance in cut Anthurium flowers in storage and its effects on quality. Acta Horticulturae 368: 723-732

Sun D W \& Wang L (2004). Experimental investigation of performance of vacuum cooling for commercial large cooked meat joints. Journal of Food Engineering 61(4): $527-532$
Teruel B, Cortez L \& Fo L N (2001). A comparative study of the cooling of oranges using three cooling systems. Revista Brasileira De Engenharia Agricola E Ambiental 5(3): 481-486

Thompson Coon J S \& Ernst E (2003). Herbs for serum cholesterol reduction: A systematic view. Journal of Family Practice 52: 468-478

Wang L J \& Sun D W (2001). Rapid cooling of porous and moisture foods by using vacuum cooling technology. Trends in Food Science \& Technology 12(5-6): 174184

Wang L J \& Sun D W (2002a). Numerical analysis of the three-dimensional mass and heat transfer with inner moisture evaporation in porous cooked meat joints during vacuum cooling. Transactions of the ASAE 45(6): 107-115

Wang L J \& Sun D W (2002b). Evaluation of performance of slow air, air blast and water immersion cooling methods in the cooked meat industry by the finite element method. Journal of Food Engineering 51(4): 329-340

Wang L J \& Sun D W (2004). Effect of operating conditions of a vacuum cooler on cooling performance for large cooked meat joints. Journal of Food Engineering 61(2): 231-240

Zhang Z \& Sun D W (2006a). Effects of cooling methods on the cooling efficiency and quality of cooked rice. Journal of Food Engineering 77: 269-274

Zhang Z \& Sun D W (2006b). Effects of cooling methods on the cooling efficiency and qualities of cooked broccoli and carrot slices. Journal of Food Engineering 77: 320-326

Zhu X F, Zhang H X \& Lo R (2004). Phenolic compounds from the leaf extract of artichoke (Cynara scolymus L.) and their antimicrobial activities. Journal of Agricultural and Food Chemistry 52: 7272-7278

Zhu X F, Zhang H X \& Lo R (2005). Antifungal activity of Cynara Scolymus L. extracts. Fitoterapia 76(1): 108-111 